\title{
EXERCISE AS AN ALTERNATIVE TO NITRITE OXIDE, AND BODY WEIGHT AND HIGH BLOOD PREASSURE: A SYSTEMATIC REVIEW
}

\author{
Tuti $^{1)}$, Ari Suwondo' ${ }^{1)}$, Sulistiyani ${ }^{2}$ \\ ${ }^{1)}$ Masters of Applied Midwifery, School of Health Polytechnic of Ministry of Health, \\ Semarang \\ 2) Faculty of Public Health, Universitas Diponegoro, Semarang
}

\begin{abstract}
Background: Hypertensive pregnancy disorders complicate $6-8 \%$ of pregnancies and cause significant maternal and fetal morbidity and mortality. Pregnancy is associated with significant changes in maternal cardiovascular system. Nitric oxide, a physiologic vascular smooth muscle relaxant regulates blood flow and therefore may play a role in the cardiovascular changes in pregnancy. While obesity is a leading risk factor for preeclampsia, the mechanisms whereby obese women are more susceptible to pregnancy-induced hypertension are unclear. This study aimed to review systematically exercise as an alternative to nitrite oxide, and body weight and high blood preassure.

Subjects and Method: A systematic review was conducted by searching the following databases included Google Scholar, Science Direct, and Pubmed which published articles from 2008 to 2018. The keywords for this review included exercise, nitrit oxide, gestasional weight again (GWG), blood pressure, hypertension in pregnancy. The inclusion criteria were quantitative, sample information, methods and research instruments, and full text . After review process 15 articles were included in this review.

Results: Almost of all articles stated that exercise effectively increased nitrite oxide level, prevented excessive weight loss, and prevented hypertension in pregnancy (80\%). Moderate intensity exercise was safe for pregnant women in the second and third trimester of pregnancy and has positive effect on newborn baby (86.7\%). The types of exercise used include aerobic exercise, stationary bikes, walking, treadmills, and yoga exercises. Exercise duration between 20 minutes to 60 minutes, with an intensity of 2 to 5 times a week.

Conclusion: Moderate intensity exercise is safe and beneficial for the health of pregnant women in preventing the occurrence of hypertension in pregnancy (preeclampsia) and metabolic syndrome.
\end{abstract}

Keywords: exercise, nitrite oxide, gestasional weight again (GWG), blood pressure, hypertension, pregnancy.

\section{Correspondence:}

Tuti. Masters of Applied Midwifery, School of Health Polytechnic of Ministry of Health Semarang. Email: tutibidan123@yahoo.co.id.

Mobile: 085390586128.

The 5th International Conference on Public Health

Best Western Premier Hotel, Solo, Indonesia, February 13-14, 2019 | 628

https://doi.org/10.26911/theicph.2019.05.20 